\title{
Promoting Innovation in Global Nursing Practice
}

\author{
Petra Brysiewicz ${ }^{1 *}$ Tonda L. Hughes ${ }^{2}$, Linda L. McCreary ${ }^{2}$ \\ ${ }^{1}$ School of Nursing and Public Health,University of KwaZulu-Natal, South Africa \\ ${ }^{2}$ College of Nursing, University of Illinois at Chicago, USA
}

\begin{abstract}
Innovation can be thought of as taking two things that already exist and putting them together in a new way. Organizations that innovate create more efficient work processes and have better productivity and performance; however, healthcare is relatively new to the science of innovation. Innovation in nursing is about encouraging nurses to use their knowledge and skills to change old ways of thinking and practicing and to develop new ways of working that improve nursing practice. It can be a daunting and challenging task to become an innovator within nursing, but innovators have the potential to improve the work environments of nurses and the quality of care and health outcomes of patients. This article provides descriptions of five inspiring nurse-led innovations and guidance regarding the way forward toward becoming an innovator. It is important to explore ways to unlock the potential for innovation to enhance quality of care and nursing interventions, always remembering that a supportive environment must be cultivated. Innovation cannot happen in isolation!
\end{abstract}

Key words: innovation; nurse; nursing innovations; nursing practice

\section{Introduction}

According to the Merriam Webster dictionary, innovation refers to a new idea, device, or method-or the act or process of introducing new ideas, devices, or methods (Merriam-Webster, 2015). Innovative behaviour can be thought of as the process of facilitating new problem solving ideas into organizational practice. Simply put, it is taking two things that already exist and putting them together in a new way.

Organizations that innovate create more efficient work processes and have better productivity and performance. Healthcare is relatively new to the science of innovation (Blakeney, Carleton, McCarthy, \& Coakley, 2009) and very few studies have examined the organizational factors that foster innovative behaviour of nursing employees (for example, see Knol \& van Linge, 2009; McSherry \& Douglas, 2011).

Creative ideas are central to the process of innovation, but ideas alone are insufficient. Although the innovation-whether a new device, process or practice-is derived from the creative process of an individual or a team, the innovation cannot be developed or sustained without an environment that is supportive of and receptive to the innovative process. Steven Johnson, author of Where good ideas come from: The natural bistory of innovation (2010), points out that some environments tend to stifle or suppress new ideas while others appear to produce them effortlessly.

What are the characteristics or attributes of an innovation environment? To answer this question, Tellis et al. (2009) examined 759 companies across 17 countries, looking for factors that predicted whether a particular organization would innovate. Although the degree of innovation was found to be influenced by external factors such as the local culture, government, and supply of labour and capital, the most important factor was the internal culture. According to the authors, innovative climates cultivate engagement and enthusiasm, challenge individuals and teams to take risks within a safe environment, foster learning, and encourage independent thinking. Similarly, in an on-line commentary published in InformationWeek, Cameron (2012) describes four attributes of a robust innovation culture. First, employees must trust that the management/supervisors support the innovation process. Such trust is built over time, for example by watching how mistakes are treated and who gets recognized and for what behaviours. Second, innovation, by definition, generally involves a process of trial and error in which mistakes are common, but from which a great deal can be learned. Supervisors and organization leaders must clearly communicate that failure is acceptable. Third, because many ideas

*Coresponding author: brysiewiczp@ukzn.ac.za 
require significant change, organizations must be flexible and support and encourage new ideas and creative approaches even when they challenge longstanding practices. Finally, open communication is essential. Employees must feel comfortable talking about their ideas openly and in a cooperative giveand-take environment.

\section{Innovation in nursing}

Innovation in nursing is about encouraging nurses to use their knowledge and skills to change the old ways of thinking and practicing and to develop new ways of working that actually improve nursing practice. It is important in order to improve the quality of care delivered, to ensure patient safety and also to reduce the cost of health care. Innovation is also vital to further develop the nursing profession and to ensure that nurses are equipped to face the challenges ahead, stay abreast with technology and service requirements and to be able to function effectively within challenging environments, such as the healthcare systems in Africa. Joseph (2015) agrees that nurses are perfectly placed to develop creative and innovative strategies that can make a huge difference in the lives of patients/clients.

It can be a daunting and challenging task to embark on the path to becoming an innovator in nursing. The nurse needs to strive to become an expert in his/ her chosen field, understanding that learning and innovation go hand in hand. Lifelong learning and professional development are essential. Nurses need to want to learn, need to want to read and be driven to explore different ways of doing things, and to challenge the status quo. In order to do this, however, it is important to have time to think and learn, to read widely and to ask lots of questions. An example of this is staying current with advances in technology, e.g., use of mobile phones, social media, and technology at the bedside. In rural South Africa a study has shown that mobile phones and social media can change learning environments and are suitable and effective tools to use to connect learners and learning (Pimmer et al., 2014).

Create something. It is important to get the ideas out of one's head and onto the page where other people can see it. The innovative nurse needs to try to test his/her ideas and see if they work or don't work. Often, in fact, the most important lessons are learnt with those plans and projects that do not work, as they provide useful lessons on what to refine and revise.

Lastly it is important to collaborate and work within a team and not for the team. Nurses can collaborate within the workplace to cultivate a culture that fosters learning and innovation. The nurse innovator needs to be very aware of the importance of listening to the ideas of others, to ask for and receive feedback, to then evaluate, refine and try again.

\section{Real world examples of nursing innovations}

There are a number of examples of innovative products and procedures that have been developed or promoted by nurses, ranging from the simple to the technologically complex, and five such examples will be described.

Faced with her HIV-positive clients' frequent bouts of oral candidiasis (thrush), and not wanting to add to their already expensive, burdensome pharmacological therapies, a nurse in India is investigating the potential of commonly available foods, honey and turmeric, to treat their thrush. Oral application of a paste made of honey and turmeric, foods known for their healing properties, will be tested for efficacy in treating and preventing thrush. If effective, this innovative approach will provide an accessible, affordable, acceptable and practical non-pharmacological solution to a very common problem that causes pain and interferes with good nutrition in many people living with HIV. This intervention may not only improve quality of life, but by enhancing nutrition, can extend length of life of this vulnerable population.

An innovative evidence-based newborn resuscitation program, Helping Babies Breathe (Singhala et al., 2012), has been implemented by nurses and midwives in many low-resource countries. Not content to provide this training solely within hospitals and health centers, nurses and midwives also teach this programme of neonatal assessment and resuscitation techniques to traditional birth attendants, who manage the majority of deliveries outside the healthcare setting. In this way, life-saving measures are being applied in community birthing settings, as well as in health facilities, and babies' lives are being saved.

Another innovative approach to saving babies' lives is being implemented in rural Haiti, where a pediatric nurse practitioner is changing cultural practices of newborn umbilical cord care. This nurse explored 
with community members the traditional practices that too often result in omphalitis (infection of the umbilicus) and the beliefs underpinning their use. She then implemented a community-wide behavioral change campaign in which antenatal clinic nurses and traditional birth attendants recommended and supported the substitution of chlorhexidine gel for unhygienic substances applied as traditional practice. Chlorhexidine gel, which has a long track record of safety and effectiveness (Walsh, Norr, Sankar, \& Sipsma, 2015), was provided to the traditional birth attendants as part of birthing packs and given to mothers at the time of delivery. Preliminary evaluation of this campaign has shown that mothers found the substitution of chlorhexidine acceptable and they refrained from applying any traditional substances as well (Walsh et al., 2015).

Nurses and midwives in Tanzania and Malawi have implemented Centering Pregnancy-Africa, an innovative model of group antenatal care adapted to the African setting (Patil et al., 2013). Antenatal appointments are given to groups of 10-12 expectant mothers at a similar gestational stage. Assessments are done individually by nurses and midwives, while interactive teaching and sharing of information is done within the group. Not only are mothers highly satisfied with this model, but nurses and midwives experience more job satisfaction and feel they are providing better care to more clients.

Finally, an example of nursing innovation is seen in nurse-managed clinics such as Integrated Health Care, award-winning clinics operated by advanced practice nurses at University of Illinois at Chicago (McDevitt, Braun, Noyes, Snyder, \& Marion, 2005). These nurse-managed clinics provide comprehensive primary care and mental health care to individuals with severe mental illness. The Integrated Health Care clinics are operated by family nurse practitioners, psychiatric/mental health nurse practitioners and a nurse midwife-all of whom have faculty appointments at the UIC College of Nursing. One physician collaborator-a psychiatrist-is also part of the clinic staff. The clinics provide clients with serious mental illnesses "one-stop" care for both their mental health needs and co-morbid conditions such as diabetes and hypertension.

\section{Challenges to innovation}

These nurse-led innovations are proof that nurses can indeed be extremely influential in finding new ways to improve patient care; however, this is very difficult to achieve within a system that does not support, nurture and encourage it. Joseph (2015) described five preconditions for innovation within an organization: organizational values (is the vision and mission supportive to innovation?), workplace relationships (does the organization try to build relationships?), organizational identification (how do members of the organization define themselves?), organizational support (does the organization value and care for the employees?) and relational leadership (does the role and style of leadership support innovation?). Innovation is not just about creating new ideas and ways of thinking, but rather about creating the climate and culture to enable this innovation to occur. Joseph (2015) recommends that nursing innovation be fundamental to the progress of the healthcare systems, and that a culture change to advance innovation is in fact needed in many organisations.

Within the resource-constrained environment of Africa it is, however, extremely difficult to attempt to create such an environment. The healthcare system in most of Africa is extremely overburdened, with too many patients and too few health workers. In many places there are limited educational opportunities for nurses to develop themselves further, and there are limited nursing mentors available to guide the nurse innovators of the future. It is very challenging to be innovative without access to recent and relevant information, for example journal articles. There is a lack of support towards staff being innovative. "If it worked for us all those years ago, why do you want to change things now?" is the attitude often encountered when nurses try to make changes or suggest innovative ways to address an issue. The nursing workplace frequently offers little support or encouragement to find different solutions to problems or new ways to do something - probably because change is very threatening and people are wary of it. Leadership may feel that being a good manager is about maintaining control of your staff, including their ideas.

\section{What Africa can teach the world}

Even though it often seems that nurses in Africa work against insurmountable odds, it is very important to realize that Africa does in fact have some lessons to teach the world regarding innovation in nursing education and practice. 
In Africa it is often a daily struggle and challenge to be a nurse and to carry out nursing care within such a resource-constrained environment. The lack of relevant resources can make nursing care a very complex task; however, Africa does teach one to be creative and resourceful. The nurse in Africa has to find ways to "make do" and to find ways around a particular obstacle; this requires the nurse to be creative with less or to devise ways to get the job done with what is available. The African Journal of Emergency Medicine has in fact recognised this unique strength in Africa and capitalized on it to develop a "resource innovation competition" (African Journal of Emergency Medicine, 2015). This competition challenged African emergency care staff to design, devise or produce a wanted resource for healthcare delivery using only locally available materials. It is often said by people who work in Africa that "If you can make it work in Africa.....you can make it work anywhere?"

Due to the situation in which they work on a daily basis, nurses in Africa appear to have developed a level of resilience; they learn how to recover quickly from the difficulties or challenges that they face. Resilience is recognised as the ability to effectively manage a situation and to turn it into a positive learning experience. Resilience is thus very important in the management of professional and organisational stress, as well as promoting innovation. For example, there is often no or limited equipment available for teaching or for clinical practice, but in the words of one clinician, nurses have to do "the best job they can, with what they have got. Often washing and reusing equipment until it falls apart ... trying to assist where possible."

Nurses in Africa have to develop a great deal of patience, as things often do not happen as planned or on time, and resources always seem to fail at the most inopportune moment. They need to develop the skills to be able to work and organize themselves within a sometimes chaotic environment and to be flexible and adaptable enough to make it work. The nurse's role requires a great deal of tolerance for uncertainty, lateral thinking and innovation.

Ubuntu is an Nguni word from South Africa, and it describes the African worldview, the essence of being human, and our interconnectedness. It means: "I am what I am because of who we all are." Ubuntu implies that people can only find true fulfilment through in- teracting with other people, and it expresses values of intense humanness, caring, sharing, respect, compassion and a happy community life in the spirit of family (Tshoose, 2009). At the heart of ubuntu is the social value of survival, which can be described as the ability to live and exist in spite of many difficulties, a collaborative spirit that allows people to share a will to survive (Poovan, Du Toit, \& Engelbrecht, 2006). The values of ubuntu underpin innovation, as it is through working together that great ideas are born and shared, thus providing the environment for change and innovation.

\section{Conclusion}

Innovation in nursing is essential. Not only is it important for all nurses to take stock and consider "what am I doing to promote innovation and am I innovative?", it is also vital that nurses explore ways to unlock our potential for innovation to enhance quality of care and nursing interventions. At the same time nurses, particularly nurse managers and supervisors, must foster a healthcare environment that nurtures innovation, remembering that innovation needs a supportive environment in which to thrive.

\section{References}

African Journal of Emergency Medicine (2015). The 2015 AfJEM Resource Innovation Competition. Retrieved from http://www.afjem.com/innovation-2015.html

Blakeney, B., Carleton, P., McCarthy, C., \& Coakley, E. (2009). Unlocking the power of innovation. The Online Journal of Issues in Nursing, 14(2). Retrieved from http://www.nursingworld.org/MainMenuCategories/ ANAMarketplace/ANAPeriodicals/OJIN / TableofContents/Vol142009/No2May09/Innovation. html

Cameron, B. (2012). 4 attributes of a robust innovation culture. Retrieved from http://www.informationweek. $\mathrm{com} /$ team-building-and-staffing/4-attributes-of-arobust-innovation-culture/d/d-id/1106396

Johnson, S. (2010). Where good ideas come from: The natural bistory of innovation. New York: Riverhead.

Joseph, M. L. (2015). Organizational culture and climate for promoting innovativeness. The Journal of Nursing Administration, 45(3), 172-178. http://dx.doi. org $/ 10.1097 /$ nna.0000000000000178

Knol, J., \& Van Linge, R. (2009). Innovative behaviour: The effect of structural and psychological empowerment on nurses. Journal of Advanced Nursing, 65(2), 359-370. http://dx.doi.org/10.1111/j.1365-2648.2008.04876.x

McDevitt, J., Braun, S., Noyes, M., Snyder, M., \& Marion, L. (2005). Integrated primary and mental health care: Evaluating a nurse-managed center for clients with 
serious and persistent mental illness. Nursing Clinics of North America, 40(4), 779-790. http://dx.doi. org/10.1016/j.cnur.2005.08.004

McSherry, R., \& Douglas, M. (2011). Innovation in nursing practice: A means to tackling the global challenges facing nurses, midwives and nurse leaders and managers in the future. Journal of Nursing Management, 19(2), 165-169. http://dx.doi.org/10.1111/j.1365-2834.2011.01241.x

Merriam-Webster. 2015. Merriam-Webster Dictionary. Encyclopaedia Britannica Company. Retrieved from http://www.merriam-webster.com/

Patil, C. L., Abrams, E. T., Klima, C., Kaponda, C. P., Leshabari, S. C., Vonderheid, S. C., \& Norr, K. F. (2013). CenteringPregnancy-Africa: A pilot of group antenatal care to address millennium development goals. Midwifery, 29(10), 1190-1198. http://dx.doi. org/10.1016/j.midw.2013.05.008

Pimmer, C., Brysiewicz, P., Linxen, S., Walters, F., Chipps, J., \& Gröhbiel, U. (2014). Informal mobile learning in nurse education and practice in remote areas- $A$ case study from rural South Africa. Nurse Education Today, 34(11),1398-1404. http://dx.doi.org/10.1016/j. nedt.2014.03.013
Poovan, N., Du Toit, M., \& Engelbrecht, A. (2006). The effect of the social values of Ubuntu on team effectiveness. South African Journal of Business Management, 37(3), 17-27.

Singhal, N., Lockyer, J., Fidler, H., Keenan, W., Little, G., Bucher, S. \& Niermeyer, S. (2012). Helping babies breathe: Global neonatal resuscitation program development and formative educational evaluation. Resuscitation, 83(1), 90-96. http://dx.doi.org/10.1016/j. resuscitation.2011.07.010

Tellis, G. J., Prabhu, J. C., \& Chandy, R. K. (2009). Radical innovation across nations: The preeminence of corporate culture. Journal of Marketing, 73(1), 3-23. http://dx.doi.org/10.1509/jmkg.73.1.3

Tshoose, C. I. (2009). The emerging role of the constitutional value of Ubuntu for informal social security in South Africa. African Journal of Legal Studies, 3(1), 12-19. http://dx.doi.org/10.1163/22109731 2x13397499736822

Walsh, S., Norr, K., Sankar, G., \& Sipsma, H. (2015). Newborn cord care practices in Haiti. Global Public Health. Advance online publication. Retrieved from http://dx.doi.org/10.1080/17441692.2015.1012094 